\title{
Application of the optimized decoupling methodology for the construction of a skeletal primary reference fuel mechanism focusing on engine-relevant conditions
}

\author{
Yachao Chang, Ming Jia*, Yaopeng Li and Maozhao Xie \\ School of Energy and Power Engineering, Dalian University of Technology, Dalian, China
}

For the multi-dimensional simulation of the engines with advanced compression-ignition combustion strategies, a practical and robust chemical kinetic mechanism is highly demanded. Decoupling methodology is effective for the construction of skeletal mechanisms for long-chain alkanes. To improve the performance of the decoupling methodology, further improvements are introduced based on recent theoretical and experimental works. The improvements include (1) updating the $\mathrm{H}_{2} / \mathrm{O}_{2}$ sub-mechanism; (2) refining the rate constants in the $\mathrm{HCO} / \mathrm{CH}_{3} / \mathrm{CH}_{2} \mathrm{O}$ sub-mechanism; (3) building a new reduced $\mathrm{C}_{2}$ sub-mechanism; and (4) improving the large-molecule sub-mechanism. With the improved decoupling methodology, a skeletal primary reference fuel (PRF) mechanism is developed. The mechanism is validated against the experimental data in shock tubes, jet-stirred reactors, and premixed and counterflow flames for various PRF fuels covering the temperature range of $500-1450 \mathrm{~K}$, the pressure range of $0.1-5.5 \mathrm{MPa}$, and the equivalence ratio range of $0.25-1.0$. Finally, the skeletal mechanism is coupled with a multi-dimensional computational fluid dynamics model to simulate the combustion and emission characteristics of homogeneous charge compression ignition $(\mathrm{HCCl})$ engines fueled with iso-octane and PRF. Overall, the agreements between the experiment and prediction are satisfactory.

Keywords: decoupling methodology, skeletal mechanism, primary reference fuel, ignition delay, laminar flame speed, homogeneous charge compression ignition

\section{Introduction}

More stringent emission regulation and increasing energy shortage motivate the development of engines with advanced combustion strategies, which can reduce emissions and improve fuel efficiency simultaneously. Nowadays, premixed low-temperature combustion (LTC) strategies, such as homogeneous charge compression ignition (HCCI) and reactivity controlled compression ignition (RCCI), attract more and more attention because of its low nitrogen oxides $\left(\mathrm{NO}_{\mathrm{x}}\right)$ and particle matter (PM) emissions and high thermal efficiency (Yao et al., 2009; Reitz and Duraisamy, 2015). In the premixed LTC mode, the ignition and combustion processes are dominantly controlled by the chemical kinetics of fuels. Thus, a robust chemical kinetic mechanism is extremely important for the simulation of the combustion and emission characteristics of the premixed LTC. 
Practical fuels contain hundreds of components with different chemical classes and a wide range of molecular weights (Ranzi, 2006; Farrell et al., 2007). It is impossible to couple the detailed chemical kinetic mechanism of practical fuels, including all the components into multi-dimensional computational fluid dynamics (CFD) simulation with the present computer resources. Therefore, primary reference fuel (PRF), i.e., the blends of iso-octane and $n$-heptane, is usually employed as an approximation to simulate the ignition and combustion characteristics of practical fuels (Ra and Reitz, 2011).

Generally, a detailed mechanism is capable of providing accurate kinetic information on the fuel ignition and oxidation processes. However, the long computational time limits the application of a detailed mechanism coupled with the multi-dimensional CFD model. To reduce the computational time, many methodologies have been proposed, which can be divided into two categories, i.e., computation acceleration and mechanism reduction.

The methodology of computation acceleration can be realized through optimization of the computation sequence, such as tabulation (Pope, 1997), dynamic reduction (Liang et al., 2009), and the coupling of both methods (Contino et al., 2011). The methodology of mechanism reduction can be achieved by removing the unimportant species and reactions with no or little accuracy loss. The representative methods of mechanism reduction include sensitivity analysis (Tomlin et al., 1992; Whitehouse et al., 2004), computational singular perturbation (CSP) (Lam and Goussis, 1994), directed relation graph (DRG) (Lu and Law, 2005, 2006), etc.

Based on the mechanism reduction methodology, a set of skeletal/reduced PRF mechanisms have been developed. Tanaka et al. (2003) built a skeletal mechanism composing of 32 species and 55 reactions to predict the ignition and oxidation characteristics of various PRFs in shock tubes, rapid compression machines (RCM), and HCCI engines. Based on a reduced $n$-heptane mechanism, Patel et al. (2004) constructed a new $n$-heptane mechanism (29 species and 52 reactions) with a series of mechanism reduction and optimization methods. The mechanism can predict the ignition delay time, pressure, and heat release traces in engines reasonably well. With the similar approach as that of Patel et al. (2004), Ra and Reitz (2008) proposed an updated PRF mechanism, including 41 species and 130 reactions. The mechanism was validated by the ignition delay time in shock tubes, pressure, heat release rate, and emissions in HCCI engines fueled with various PRFs.

It should be noted that the aforementioned reduced mechanisms are only validated against the experimental data of ignition delay time in shock tubes, RCMs, and engines. Liu et al. (2012) found that the laminar flame speed and major species evolutions in jet-stirred reactor (JSR) cannot be well reproduced by the above reduced PRF mechanisms. Recently, based on the DRG method, Wang et al. (2013) obtained a reduced PRF mechanism consisting of 73 species and 296 reactions. It was found that the predicted ignition delay times, flame speeds, major species evolutions, pressure, and heat release rate profiles in engines are in good agreement with the measurements. By combining the DRG method, isomer lumping method, and timescale analysis, Luong et al. (2013) reduced a detailed PRF mechanism to a 171-species reduced mechanism. The mechanism is validated by comparing the predicted ignition delay times, temperature profiles, and laminar flame speeds with those of the detailed mechanism.

From comparison of the available skeletal/reduced PRF mechanisms with the measured ignition delay time, laminar flame speed, and major species concentrations over a wide range of temperature, pressure, and equivalence ratio for various PRFs (see the results presented in the Supplementary Material), it is found that there are still some discrepancies between the predictions from the available PRF mechanisms and the measurements. This could be primarily due to the objective and method for the development of these mechanisms. For the skeletal mechanisms, the reaction pathways and reaction rates are usually determined in an empirical way with particular attention on the prediction of the ignition delay behavior in order to keep the mechanism size as small as possible. Thus, the characteristics of flame propagation cannot be satisfactorily reproduced by the skeletal mechanisms. By contrast, for the reduced mechanisms, a series of reduction methods are employed to reduce a detailed mechanism in the specified operating conditions. Consequently, the performance of the reduced mechanisms strongly depends on the operating conditions. Furthermore, it is still a challenge to reduce a detailed mechanism with hundreds of species to an extremely simplified one, which is highly desired in multi-dimensional CFD simulations.

In our previous paper, a decoupling methodology was proposed, with which a skeletal PRF mechanism was developed (Liu et al., 2012). By comparing with the experimental data in shock tubes, JSRs, flow reactors, premixed and counterflow flames, and HCCI engines, the PRF mechanism show good agreements with the measurements. However, it is recently found that the PRF mechanism cannot predict the ignition delay time well at $\varphi<0.5$. Moreover, the laminar flame speed and low-temperature heat release in engine simulations cannot be also reproduced accurately.

In this study, the decoupling methodology is improved based on the latest theoretical and experimental works. Then, a new skeletal PRF mechanism is developed using the improved decoupling methodology with special attentions on engine simulations. By validating with the experimental data in various fundamental reactors and HCCI engines over a wide range of operating conditions, it is found that the present PRF mechanism is capable of satisfactorily reproducing the ignition and heat release processes, the evolution of major reactants and products, and laminar flame speed.

\section{Computational Method}

\section{Decoupling Methodology}

The decoupling methodology has been described in detail in Chang et al. (2013a), and only a brief description is presented herein. In the decoupling methodology, a detailed $\mathrm{H}_{2} / \mathrm{CO} / \mathrm{C}_{1}$ mechanism is used to predict the evolution of small radicals and species, heat release rate, and laminar flame speed, while ignition delay time and fuel consumption are controlled by a skeletal large-molecule mechanism. A reduced $\mathrm{C}_{2}-\mathrm{C}_{3}$ mechanism serves as the transition between the skeletal large-molecule mechanism and the detailed $\mathrm{H}_{2} / \mathrm{CO} / \mathrm{C}_{1}$ mechanism. With the decoupling methodology, a series of skeletal mechanisms for normal and 
branched alkanes have been constructed (Liu et al., 2012; Chang et al., 2013b). By comparing with experimental data, it is found that the mechanisms can satisfactorily reproduce the auto-ignition and oxidation behaviors from low to high temperatures in various reactors and practical engines. Since a skeletal mechanism is introduced for large-molecule species, the size of the final mechanism can be kept extremely small, which is attractive for the simulations of engine combustion processes.

However, it was recently discovered that the previous PRF mechanism (Liu et al., 2012) cannot well predict the lowtemperature ignition characteristics at equivalence ratios below 0.5 , and the low-temperature heat release in HCCI engines. Moreover, the influence of fuel molecular structure on laminar flame speed is not well captured by the PRF mechanism. To improve the performance of the PRF mechanism, further improvements are introduced to the decoupling methodology based on recent theoretical and experimental works in this study.

\section{Optimized Process $\mathrm{H}_{2} / \mathrm{O}_{2}$ Sub-Mechanism}

The $\mathrm{H}_{2} \mathrm{O}_{2}$ sub-mechanism is the base of the oxidation mechanisms for all hydrocarbon (HC) and oxygenated fuels (Westbrook and Dryer, 1984). It was found that the $\mathrm{H}_{2} / \mathrm{O}_{2}$ mechanism considerably affects the predictions of auto-ignition and flame speed characteristics for large-molecule fuels (Bikas and Peters, 2001; Ji et al., 2012; Narayanaswamy et al., 2014). Thus, a reliable $\mathrm{H}_{2} / \mathrm{O}_{2}$ mechanism is crucial for the development of the PRF mechanism. In previous studies, the $\mathrm{H}_{2} / \mathrm{O}_{2}$ mechanism developed by Li et al. (2004) is usually introduced as the core for the mechanisms of large-molecule hydrocarbons. Recently, Burke et al. (2012) further updated the $\mathrm{H}_{2} / \mathrm{O}_{2}$ mechanism of Li et al. (2004), and significant improvements were achieved, especially under high-pressure and dilution conditions. Therefore, the updated $\mathrm{H}_{2} / \mathrm{O}_{2}$ mechanism (Burke et al., 2012) is used in this study.

Figure 1 compares the predicted ignition delay time and laminar flame speed using the previous mechanism and the improved one with the updated $\mathrm{H}_{2} / \mathrm{O}_{2}$ mechanism (Change I). As can be seen in Figure 1A, the $\mathrm{H}_{2} / \mathrm{O}_{2}$ mechanism slightly affects the ignition delay time at temperatures below $1000 \mathrm{~K}$, which is primarily caused by the improved reaction rate of $\mathrm{H}_{2} \mathrm{O}_{2}(+\mathrm{M})=\mathrm{OH}+\mathrm{OH}(+\mathrm{M})$ because of its high sensitivity to temperature in the negative temperature coefficient (NTC) regime (Narayanaswamy et al., 2014). It can be seen from Figure 1B that, although the updated mechanism improves the predictions on laminar flame speed, laminar flame speed is still overestimated when equivalence ratio $(\varphi)$ is larger than 0.9 for iso-octane and
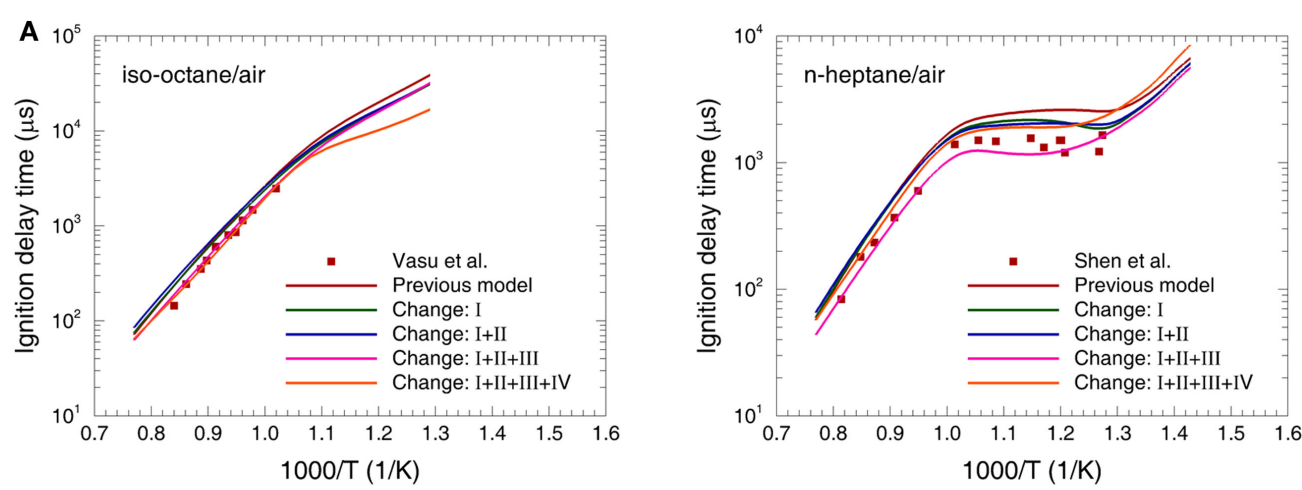

Ignition delay time $(p=4.5 \mathrm{MPa}, \varphi=0.25)$
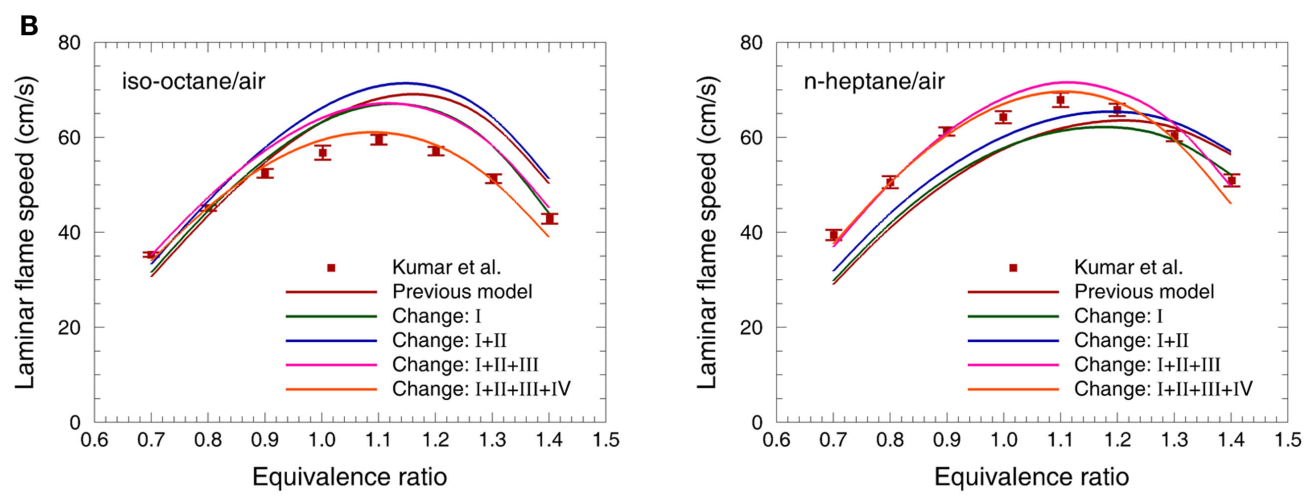

laminar flame speed $\left(p=0.1 \mathrm{MPa}, T_{u}=400 \mathrm{~K}\right)$

FIGURE 1 | Influence of different improvements introduced to the previous PRF mechanism on (A) the predicted ignition delay time at $p=4.5 \mathrm{MPa}$ and $\varphi=0.25$, and (B) laminar flame speed at $p=0.1 \mathrm{MPa}$ and $T_{\mathrm{u}}=400 \mathrm{~K}$ [(I) updated $\mathrm{H}_{2} / \mathrm{O}_{2}$ chemistry; (II) updated $\mathrm{HCO} / \mathrm{CH}_{3} / \mathrm{CH}_{2} \mathrm{O}$ sub-mechanism; (III) updated $\mathrm{C}_{2}$ sub-mechanism; (IV) updated large-molecule sub-mechanism] [symbols are experimental data (Vasu et al., 2005; Kumar et al., 2007; Shen et al., 2009); lines are predicted results]. 
is underestimated at $\varphi<1.3$ for $n$-heptane. The differences in the predicted laminar flame speed between the previous mechanism and the updated mechanism are mainly resulted from the variation of the rate constants of the reactions $\mathrm{H}+\mathrm{O}_{2}=\mathrm{O}+\mathrm{OH}$ and $\mathrm{H}+\mathrm{O}_{2}(+\mathrm{M})=\mathrm{HO}_{2}(+\mathrm{M})$, which dominate the laminar flame speed of hydrocarbons (Ji et al., 2012; Ranzi et al., 2012).

\section{$\mathrm{HCO} / \mathrm{CH}_{3} / \mathrm{CH}_{2} \mathrm{O}$ Sub-Mechanism}

The decomposition of formyl (HCO) radical dominates the formation of carbon monoxide (CO) at high temperatures for the oxidation of hydrocarbons. Metcalfe et al. (2013) recommended an updated $\mathrm{HCO}$ decomposition reaction, in which the reaction rate is increased by $20 \%$ compared to that proposed by Li et al. (2007). It was found that the slight change considerably improved the predicted laminar flame speed for methanol, especially under fuellean conditions (Metcalfe et al., 2013). Therefore, the improved rate constants for $\mathrm{HCO}$ decomposition are included in the present mechanism.

The methyl $\left(\mathrm{CH}_{3}\right)$ radical plays a very important role for the flame of hydrocarbons (Ranzi et al., 2012). Previous studies found that the reactions involved $\mathrm{CH}_{3}$ radical significantly affected the laminar flame speed and ignition delay time for a variety of fuels (Chaos et al., 2007; Ji et al., 2010, 2012; Ranzi et al., 2012). Metcalfe et al. (2013) proposed a new $\mathrm{CH}_{3}$ chemical mechanism based on recent theoretical and experimental works. It was indicated that the mechanism with the new $\mathrm{CH}_{3}$ sub-mechanism was capable of accurately predicting the ignition delay time and laminar flame speed of methane over a wide range of conditions (Metcalfe et al., 2013).

Furthermore, formaldehyde $\left(\mathrm{CH}_{2} \mathrm{O}\right)$ is crucial for the oxidation of long-chain hydrocarbons in the cool flame and NTC regimes (Campbell et al., 2015), which are closely associated with the autoignition for practical engines in the LTC mode. In the present mechanism, the $\mathrm{CH}_{2} \mathrm{O}$ sub-mechanism is also refined based on the work of Metcalfe et al. (2013).

Overall, it can be seen from Figure 1 that the mechanism using the updated $\mathrm{HCO} / \mathrm{CH}_{3} / \mathrm{CH}_{2} \mathrm{O}$ sub-mechanism (Change I + II) slightly affects the predicted ignition delay time, whereas the predicted laminar flame speed significantly increases for both $n$-heptane and iso-octane.

\section{$\mathrm{C}_{2}$ Sub-Mechanism}

In the previous decoupling methodology, the core mechanism is a detailed $\mathrm{H}_{2} / \mathrm{CO} / \mathrm{C}_{1}$ mechanism, and the oxidation of $\mathrm{C}_{2}$ species is described by an extremely reduced mechanism. However, Warnatz (1981) found that excessively reduced $C_{2}$ mechanism was insufficient for the predictions in fuel-rich flames. Moreover, Ji et al. (2012) indicated that the concentration of vinyl $\left(\mathrm{C}_{2} \mathrm{H}_{3}\right)$ increased rapidly with the decreased number of molecular branch, which led to increased laminar flame speed. Unfortunately, the previous PRF mechanism (Liu et al., 2012) cannot accurately capture this behavior. To solve this problem, the $\mathrm{C}_{2}$ sub-mechanism is improved by introducing a series of reactions involving $\mathrm{C}_{2} \mathrm{H}_{3}$ and $\mathrm{C}_{2} \mathrm{H}_{4}$ due to their importance in ignition and flame propagation behaviors (Metcalfe et al., 2013). The related reactions are obtained by sensitivity and reaction flow analysis on onedimensional laminar flames for the detailed mechanisms of Ji et al. (2012), Ranzi et al. (2012), and Metcalfe et al. (2013).
As shown in Figure 1, the predicted ignition delay times and laminar flame speeds using the updated $\mathrm{C}_{2}$ sub-mechanism (Change I + II + III) show better agreement with the experiment data for both fuels. Especially, the laminar flame speed of $n$-heptane is higher than that of iso-octane at the same operating conditions (Kumar et al., 2007), which is satisfactorily reproduced by the present PRF mechanism. However, the previous mechanism cannot capture this phenomenon. Although the predicted ignition delay time and laminar flame speed are relatively insensitive to the reactions involving $\mathrm{C}_{2}$ species for the cases tested in this study (see Figures 4 and 10), as the transition between large species and small species, the reaction paths in the $\mathrm{C}_{2}$ submechanism strongly affects the formation of small radicals and species. Therefore, the enhancement of the $C_{2}$ chemistry is still very important for the development of the PRF mechanism.

\section{Large-Molecule Sub-Mechanism}

In most previous reduced and skeletal mechanisms, the forward and reverse rate constants for the large-molecule reactions are usually adjusted separately in order to well reproduce the ignition and oxidation behaviors of fuels. However, it is well known that the reverse reaction rate should be calculated by the forward reaction rate and the equilibrium constant using the thermodynamic data of the related species. To be consistent with the theory of chemical kinetics, the reverse reaction rate is directly calculated on the basis of the equilibrium constant instead of artificial assignment in the present PRF mechanism.

By comparing the laminar flame speeds of $n$-heptane and isooctane, Ranzi et al. (2012) indicated that one of the reasons for the lower laminar flame speed of iso-octane than $n$-heptane was the formation of isobutene $\left(i \mathrm{C}_{4} \mathrm{H}_{8}\right)$ during the oxidation of iso-octane. In the iso-octane flame, the $\beta$-scission of $\mathrm{C}_{8} \mathrm{H}_{17}$ (R18) is the major pathway for the formation of $i \mathrm{C}_{4} \mathrm{H}_{8}$, and $i \mathrm{C}_{4} \mathrm{H}_{8}$ is consumed subsequently via the $\mathrm{H}$-abstract reactions by $\mathrm{H}$ (R28) and $\mathrm{OH}$ (R29) (Ji et al., 2012). Then, $i \mathrm{C}_{4} \mathrm{H}_{9}$ and $i \mathrm{C}_{4} \mathrm{H}_{7}$ undergo decomposition reactions, and form $\mathrm{C}_{3} \mathrm{H}_{6}+\mathrm{CH}_{3}(\mathrm{R} 30)$ and $\mathrm{C}_{3} \mathrm{H}_{4}+\mathrm{CH}_{3}$ (R31), respectively.

$$
\begin{aligned}
& \mathrm{C}_{8} \mathrm{H}_{17}<=>i \mathrm{C}_{4} \mathrm{H}_{8}+i \mathrm{C}_{4} \mathrm{H}_{9} \\
& i \mathrm{C}_{4} \mathrm{H}_{8}+\mathrm{H}<=>i \mathrm{C}_{4} \mathrm{H}_{7}+\mathrm{H}_{2} \\
& i \mathrm{C}_{4} \mathrm{H}_{8}+\mathrm{OH}<=>i \mathrm{C}_{4} \mathrm{H}_{7}+\mathrm{H}_{2} \mathrm{O} \\
& i \mathrm{C}_{4} \mathrm{H}_{9}<=>\mathrm{C}_{3} \mathrm{H}_{6}+\mathrm{CH}_{3} \\
& i \mathrm{C}_{4} \mathrm{H}_{7}<=>\mathrm{C}_{3} \mathrm{H}_{4}+\mathrm{CH}_{3}
\end{aligned}
$$

Furthermore, Andrae et al. (2005) found that the co-oxidation reactions between different fuel molecules and the related radicals were important at low temperatures for the oxidation of multicomponent fuels. To account for the contribution of co-oxidation reactions, the reaction from $\mathrm{Ra}$ and Reitz (2008) is added in the present PRF mechanism.

$$
\mathrm{C}_{8} \mathrm{H}_{18}+\mathrm{C}_{7} \mathrm{H}_{15}<=>\mathrm{C}_{7} \mathrm{H}_{16}+\mathrm{C}_{8} \mathrm{H}_{17}
$$

After determining the reaction paths, the rate constants of the large-molecule reactions are slightly optimized in order to remove the influence of the elimination of large-molecule isomers in the present mechanism. The detailed optimization process is 
presented in our previous study (Chang et al., 2013a), and only a brief description is presented herein.

The optimization process is primarily focused on the reactions involving the large-molecule species. First, the initial rate constants of the large-molecule reactions are obtained from those of the related reactions in the detailed mechanisms; second, sensitivity analysis on ignition delay time is performed to identify the important reactions. The rate constants of these reactions are optimized to accurately reproduce the ignition delay time in shock tubes over wide operating conditions; third, further optimization is conducted to satisfactorily predict the major species evolutions in JSRs by path analysis and rate of production (ROP) analysis; and finally, the above two steps are iterated until the predicted ignition delay time and major species concentrations are within accepted tolerances.

It can be seen from Figure $\mathbf{1 A}$ that the mechanism with the updated large-molecule sub-mechanism (Change I + II + III + IV) predicts shorter ignition delay times for iso-octane at temperatures below $950 \mathrm{~K}$ and longer ignition delay times for $n$-heptane over the whole temperature range, which are more consistent with the measurements than the mechanism without optimization (Change I + II + III). As can be found from Figure 1B, the higher flame speed of $n$-heptane than iso-octane can also be satisfactorily reproduced by the updated mechanism. Although the large-molecule reactions have insignificant influence on laminar flame speed (Babushok and Tsang, 2004), the predicted flame speed is still slightly changed with the improvement of the $n$-heptane sub-mechanism, which is primarily because of the variation of the formation pathways of small species from large-molecule species in the PRF mechanism. For the laminar flame speed of iso-octane, the predictions using the improved mechanism are notably reduced due to the introduction of the stable intermediate $i \mathrm{C}_{4} \mathrm{H}_{8}$ compared to the previous mechanism (Liu et al., 2013).

In general, based on the optimized decoupling methodology, the present updated PRF mechanism illustrates better agreement with the measured ignition delay time and laminar flame speed for both $n$-heptane and iso-octane compared to the previous mechanism in Figure 1. The final PRF mechanism consists of 49 species and 163 reactions. In the present mechanism, the thermodynamic and transport properties of $\mathrm{C}_{0}-\mathrm{C}_{3}$ species and $\mathrm{C}_{4}-\mathrm{C}_{8}$ species are taken from the work of Metcalfe et al. (2013) and Mehl et al. (2011), respectively.

\section{Mechanism Validations}

In this section, the improved PRF mechanism developed based on the optimized decoupling methodology is further validated by the measurements in shock tubes, JSRs, premixed laminar flames, and laminar flame speed over a wide range of operating conditions. In addition, the PRF mechanism is coupled with 3D CFD model to simulate the combustion and emission characteristics of HCCI engines fueled with iso-octane and PRF.

\section{Shock Tube}

The calculated ignition delay times of $n$-heptane and iso-octane are compared with the experimental data (Ciezki and Adomeit, 1993; Fieweger et al., 1997; Gauthier et al., 2004; Vasu et al., 2005; Shen et al., 2008, 2009; Heufer and Olivier, 2010) over low-tohigh temperatures and pressures at $\varphi=0.25$ and 1.0 in Figures 2 and 3. It can be seen that the predicted ignition delay times are in good agreement with the measurements over the whole operating conditions. To recognize the reactions dominating the ignition delay time at different temperature regimes, a sensitivity analysis is performed for iso-octane and $n$-heptane at $p=4.0 \mathrm{MPa}$, $\varphi=1.0$, and $T=700,850$, and $1100 \mathrm{~K}$ in Figure 4, which represents the low-temperature, NTC, and high-temperature regimes, respectively.

As shown in Figure 4, the fuel-specific reactions display high sensitivity on the predicted ignition delay times at all the three temperatures, especially for the $\mathrm{H}$-atom abstraction reactions and fuel alkyl decomposition reactions. Moreover, the chemistry of $\mathrm{CH}_{3}, \mathrm{CH}_{2} \mathrm{O}$, and $\mathrm{H}_{2}$ also affects the ignition delay time for both $n$-heptane and iso-octane. Thus, a refinement of the chemical kinetics for these small species can also improve the predicted ignition delay time.

The addition of exhaust gas recirculation (EGR) is an effective way to reduce the in-cylinder charge temperature in practical
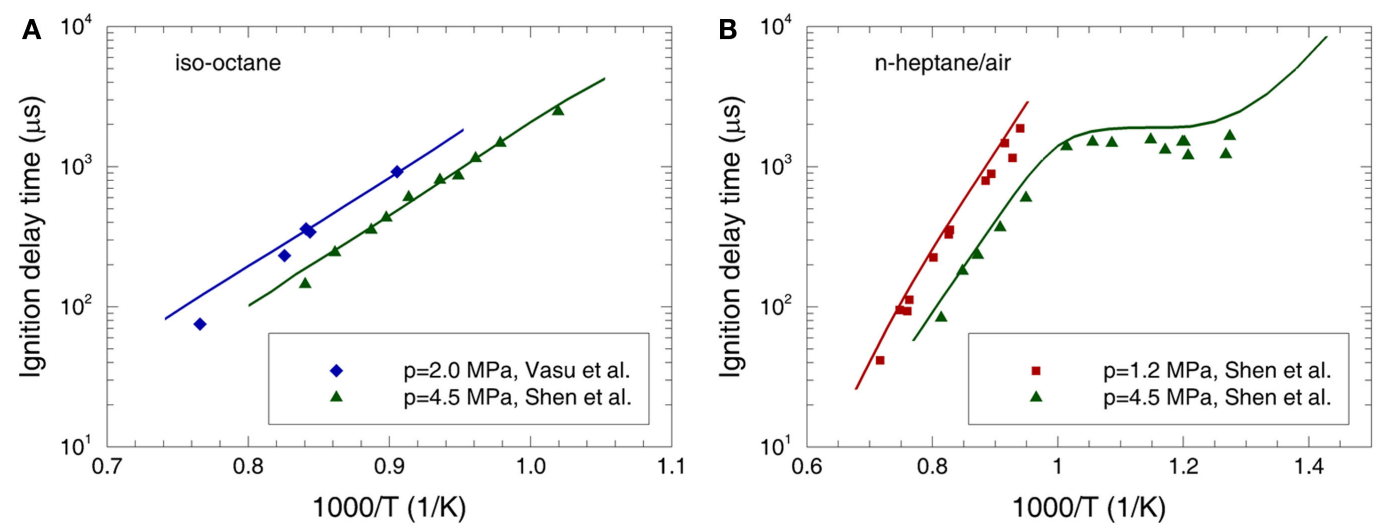

FIGURE 2 | Experimental (symbols) and predicted (lines) ignition delay times at $\varphi=0.25$ for (A) iso-octane/air mixture (Vasu et al., 2005; Shen et al., 2008) and (B) $n$-heptane/air mixture (Shen et al., 2009). 

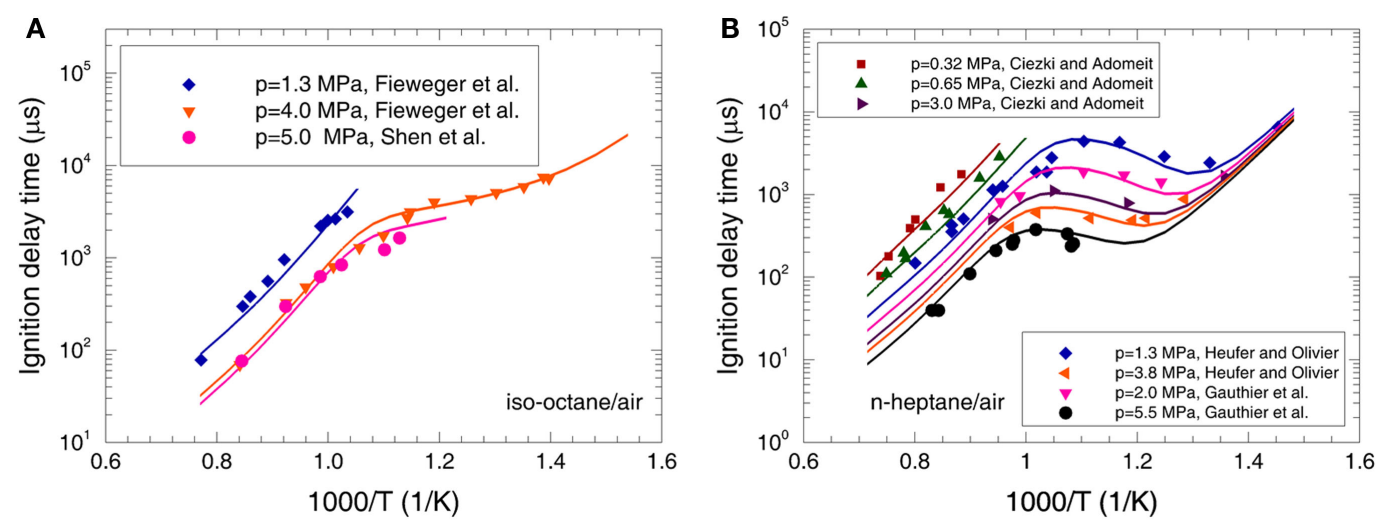

FIGURE 3 | Experimental (symbols) and predicted (lines) ignition delay times at $\boldsymbol{\varphi = 1 . 0}$ for (A) iso-octane/air mixture (Fieweger et al., 1997; Shen et al., 2008) and (B) $\boldsymbol{n}$-heptane/air mixture (Ciezki and Adomeit, 1993; Gauthier et al., 2004; Heufer and Olivier, 2010)
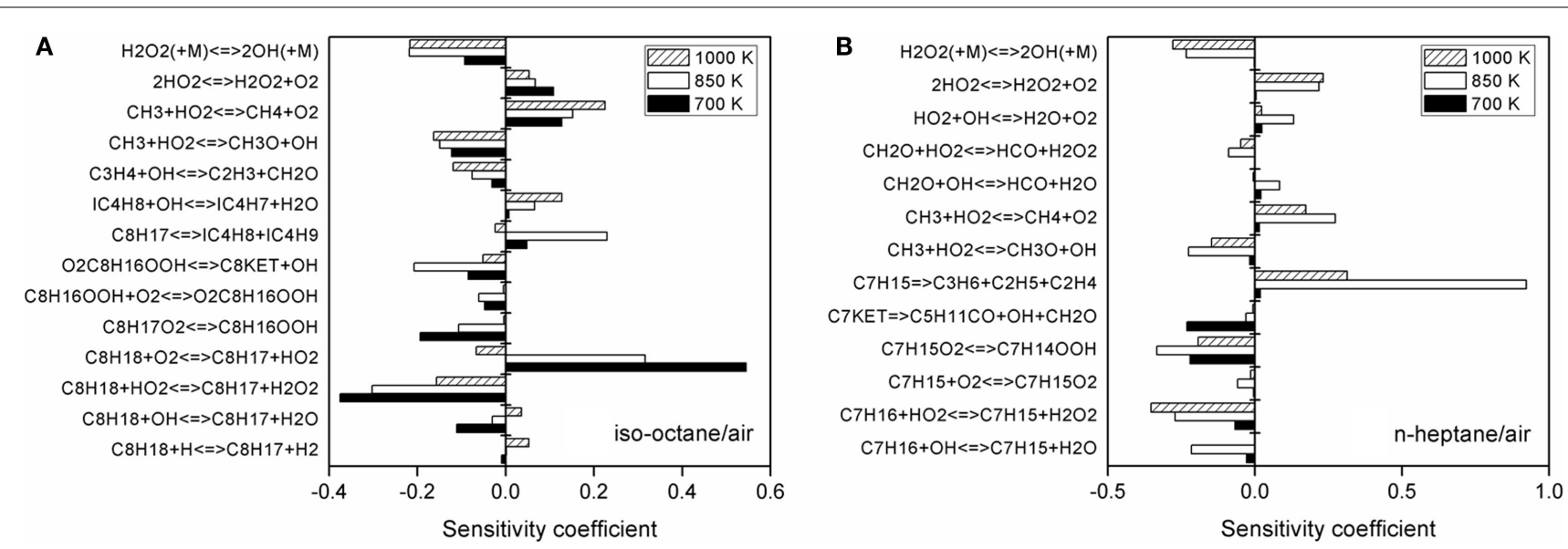

FIGURE 4 | Sensitivity analysis of ignition delay time at $p=4.0 \mathrm{MPa}$ and $T=700,850$, and $1100 \mathrm{~K}$ for $(\mathrm{A})$ iso-octane/air and (B) $n$-heptane/air.

engines, which can considerably reduce $\mathrm{NO}_{\mathrm{x}}$ emissions. To understand the influence of EGR on the ignition behavior of fuel/air mixture, Vandersickel et al. (2012) measured the ignition delay time of $n$-heptane/air/EGR in a high-pressure shock tube covering the temperature range of $700-1100 \mathrm{~K}$ and various EGR rates. In the experiment, the EGR gas was mimicked by $\mathrm{N}_{2}$. Comparisons between the measured and calculated ignition delay times are shown in Figure 5. It can be found that the present mechanism predicts the ignition delay time reasonably well at the investigated conditions. Moreover, the dependence of ignition delay time on EGR rate is also satisfactorily reproduced.

The ignition delay times of various PRFs are studied by Fieweger et al. (1997) in a shock tube for the temperatures from 700 to $1300 \mathrm{~K}$ at $p=4.0 \mathrm{MPa}$ and $\varphi=1.0$. The predicted ignition delay times are compared to the experimental data in Figure 6. Good agreement between the predictions and measurements can be observed for various PRFs. Furthermore, it can be seen that the ignition delay time increases with increased octane number $(\mathrm{ON})$ at the low-temperature and NTC regimes. However, the influence of $\mathrm{ON}$ on ignition delay time at high temperatures is

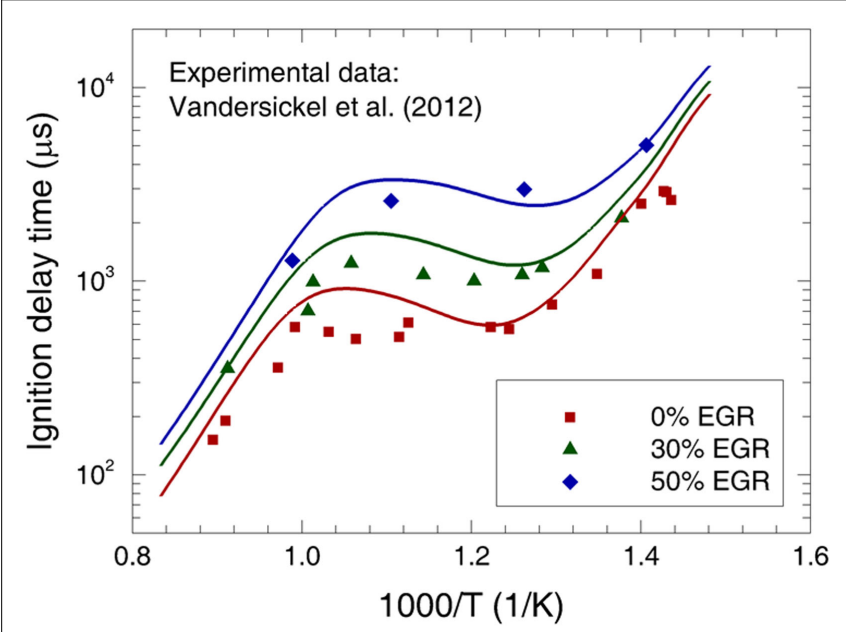

FIGURE 5 | Experimental (symbols) and predicted (lines) ignition delay times at $\varphi=0.67$ and $p=4.0 \mathrm{MPa}$ for various $n$-heptane/air/EGR mixtures (Vandersickel et al., 2012). 


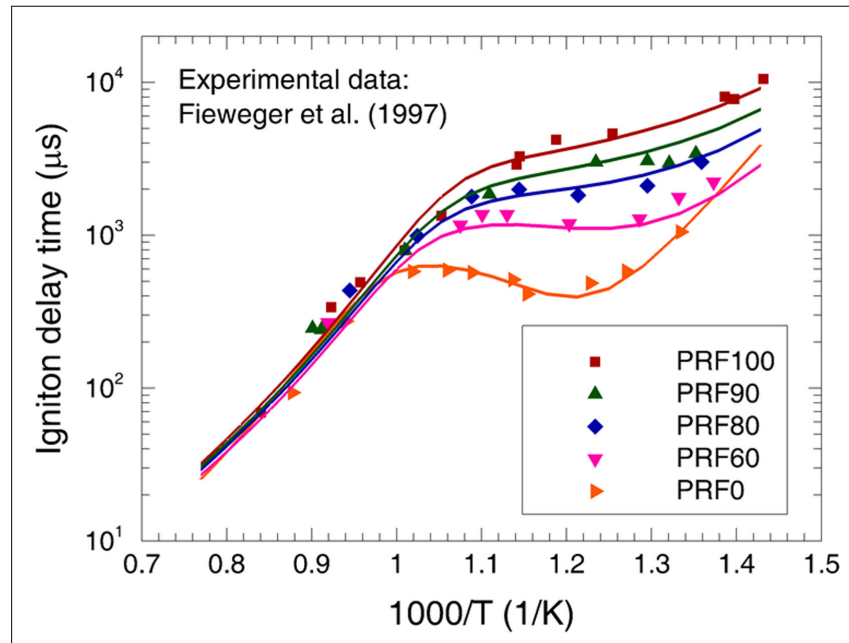

FIGURE 6 | Experimental (symbols) and predicted (lines) ignition delay times at $\varphi=1.0$ and $p=4.0 \mathrm{MPa}$ for PRF fuels/air mixtures (Fieweger et al., 1997).

very weak. All these behaviors are accurately reproduced by the present mechanism, as shown in Figure 6.

\section{Jet-Stirred Reactor}

Dagaut et al. (1993, 1994) investigated the oxidation of isooctane and various PRFs in a high-pressure JSR from 550 to $1150 \mathrm{~K}$ at $p=1.0 \mathrm{MPa}$ and $\varphi=1.0$ with the residence time $(\tau)$ of $1 \mathrm{~s}$. Recently, Herbinet et al. (2012) measured the oxidation of $n$-heptane $/ \mathrm{O}_{2} / \mathrm{He}$ in a JSR over the temperature range of $500-1100 \mathrm{~K}$ at $p=0.1 \mathrm{MPa}$ and $\varphi=1.0$ with $\tau=2 \mathrm{~s}$.

Comparisons between the measured and predicted mole fraction of major species are shown in Figure 7. As can be seen, satisfactory agreements between the measurements and predictions are achieved for all the test fuels. An evident NTC phenomenon is observed at the temperatures between 620 and $740 \mathrm{~K}$ on the concentration profiles of $\mathrm{O}_{2}, \mathrm{C}_{7} \mathrm{H}_{16}$, and $\mathrm{CO}$ for $n$ heptane $/ \mathrm{O}_{2} / \mathrm{He}$ mixture, whereas it is not found for iso-octane and PRF90. As shown in Figure 7B, the location and amplitude of the NTC region are reproduced by the present mechanism quite well, although some discrepancies exist in the CO profile. In the NTC region, the oxidation of $n$-heptane is governed by the lowtemperature mechanism (R7-R12), hence enhancement of the low-temperature sub-mechanism can improve the predicted $\mathrm{CO}$ concentration. Similar offset of the NTC region in the CO profile is reported by Herbinet et al. (2012) and Wang et al. (2013). No further refinement is performed in this study because the results presented in Figure 7 B are obtained under atmospheric pressure, which is far from the engine-relevant conditions. Moreover, it can be seen from Figure $7 \mathrm{~A}$ that the evolution of $i \mathrm{C}_{4} \mathrm{H}_{8}$ is predicted reasonably well, although a simplified $i \mathrm{C}_{4} \mathrm{H}_{8}$ sub-mechanism is used in the present PRF mechanism. Due to a relatively reliable $\mathrm{CH}_{2} \mathrm{O}$ sub-mechanism being included, the mole fraction of $\mathrm{CH}_{2} \mathrm{O}$ is also predicted well in Figure 7A.

As shown in Figure 7A, the mole fraction profile of $\mathrm{H}_{2}$ is predicted satisfactorily for iso-octane $/ \mathrm{O}_{2} / \mathrm{N}_{2}$ mixture. However,

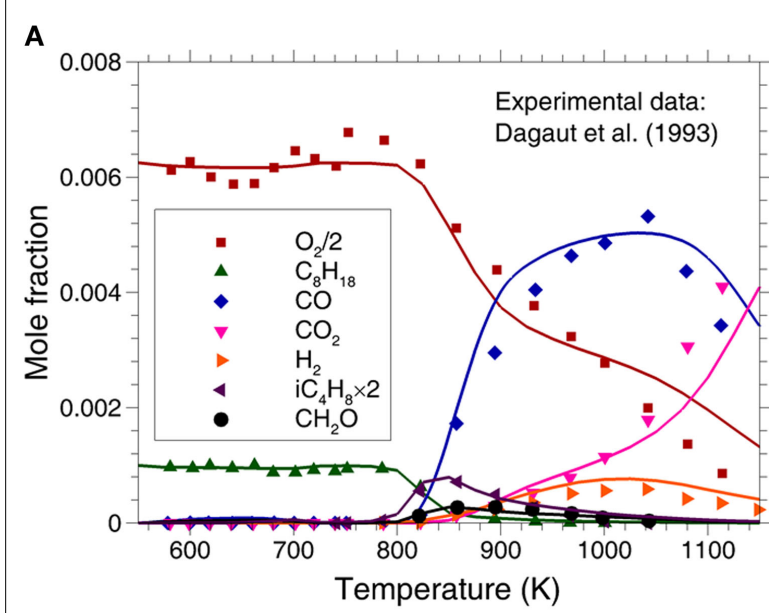

$0.1 \%$ iso-octane $/ \mathrm{O}_{2} / \mathrm{N}_{2}, \tau=1 \mathrm{~s}, \varphi=1.0, p=1.0 \mathrm{MPa}$

B

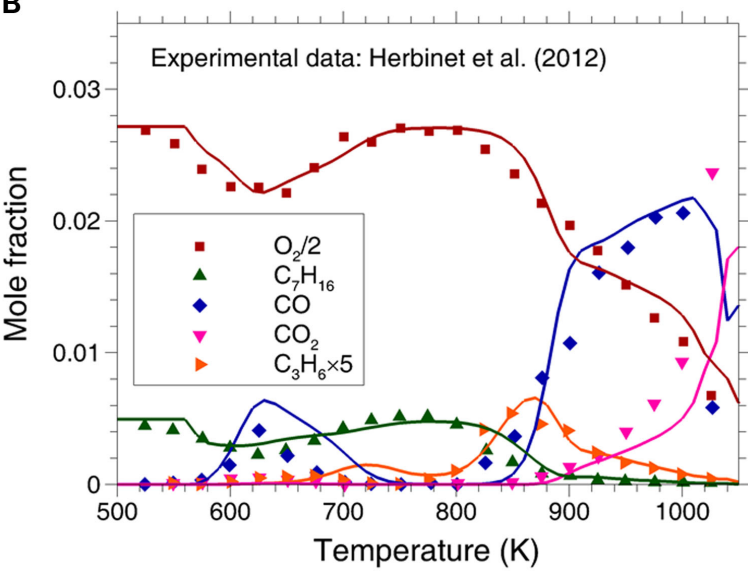

$0.5 \% n$-heptane $/ \mathrm{O}_{2} / \mathrm{He}, \tau=2 \mathrm{~s}, \varphi=1.0, p=0.1 \mathrm{MPa}$

C

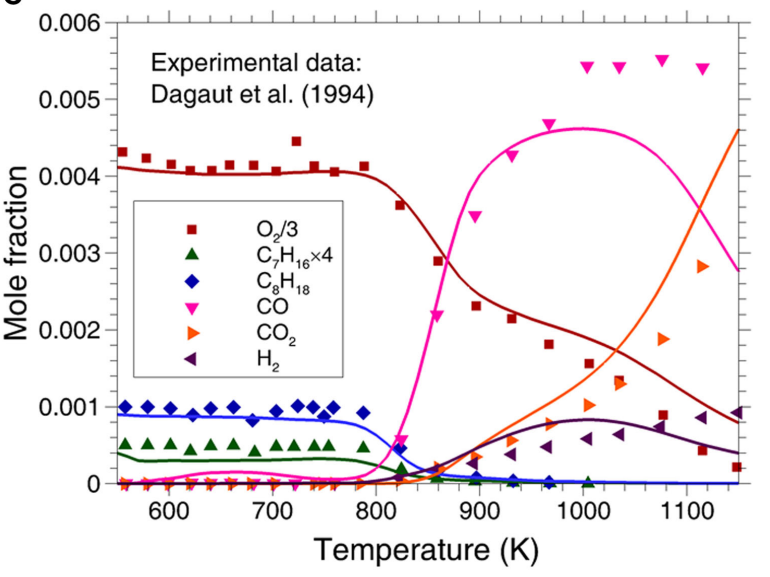

$0.1 \% \mathrm{PRF} 90 / \mathrm{O}_{2} / \mathrm{N}_{2}, \tau=1 \mathrm{~s}, \varphi=1.0, p=1.0 \mathrm{MPa}$

FIGURE 7 | Experimental (symbols) and predicted (lines) mole fraction of major species in JSR for (A) iso-octane $/ \mathrm{O}_{2} / \mathrm{N}_{2}$ (Dagaut et al., 1993); (B) $n$-heptane $/ \mathrm{O}_{2} / \mathrm{He}$ (Herbinet et al., 2012); and (C) $\mathrm{PRF} 90 / \mathrm{O}_{2} / \mathrm{N}_{2}$ (Dagaut et al., 1994). 
the deviation between the predictions and measurements for $\mathrm{H}_{2}$ concentration is obvious at temperatures above $1060 \mathrm{~K}$ and $p=1.0 \mathrm{MPa}$ for $\mathrm{PRF} 90 / \mathrm{O}_{2} / \mathrm{N}_{2}$ mixture in Figure $7 \mathrm{C}$. Based on ROP analysis, it is found that the $\mathrm{H}_{2}$ evolution during the oxidation of PRF is dominantly controlled by the sub-mechanism of small species, especially the $\mathrm{H}_{2}$ mechanism. Recently, study indicated that the present available $\mathrm{H}_{2}$ mechanisms cannot work well at high pressures (Li et al., 2015). Thus, further refinement of the $\mathrm{H}_{2}$ mechanism in a wide temperature and pressure range is still needed in the future work.

\section{Premixed Laminar Flame}

Bakali et al. (1998) measured the species concentrations for the laminar premixed $n$-heptane $/ \mathrm{O}_{2} / \mathrm{N}_{2}$ and iso-octane $/ \mathrm{O}_{2} / \mathrm{N}_{2}$ flames in a flat-flame burner at atmospheric pressure. The experiment is simulated using the PREMIX module in the CHEMKIN-PRO Release 15101 (2010). In the simulation, the measured temperature profile is employed as the input parameter with a shift of $0.5 \mathrm{~mm}$ away from the burner surface to account for the perturbation induced by the probe and thermocouple (Hansen et al., 2009; Skeen et al., 2011). The temperature shift is estimated in this study based on the best agreement between the predictions and measurements on the species profiles. Comparisons between the predicted and measured species concentrations for the two flames are shown in Figure 8. Considering the uncertainties in the experiment, it can be concluded that the present mechanism is capable of reproducing the major species concentration profiles very well.

\section{Laminar Flame Speed}

The laminar flame speed is an important combustion parameter, which is determined by the reactivity, diffusivity, and exothermicity of fuels. Thus, the laminar flame speeds of various PRFs are used to evaluate the performance of the present mechanism in this section. The PREMIX module in the CHEMKIN-PRO Release 15101 (2010) is employed for the simulation.

The laminar flame speeds of iso-octane/air and $n$-heptane/air were measured by Kumar et al. (2007) with a counterflow flame technique over the equivalence ratio range of $0.7-1.4$ and unburned mixture temperatures $\left(T_{\mathrm{u}}\right)$ of $298,360,400$, and $470 \mathrm{~K}$ at atmospheric pressure. Figure 9 compares the predicted laminar flame speed of iso-octane/air and $n$-heptane/air mixtures to the experimental data. It can be seen that the present mechanism can capture the variation of laminar flame speed with the
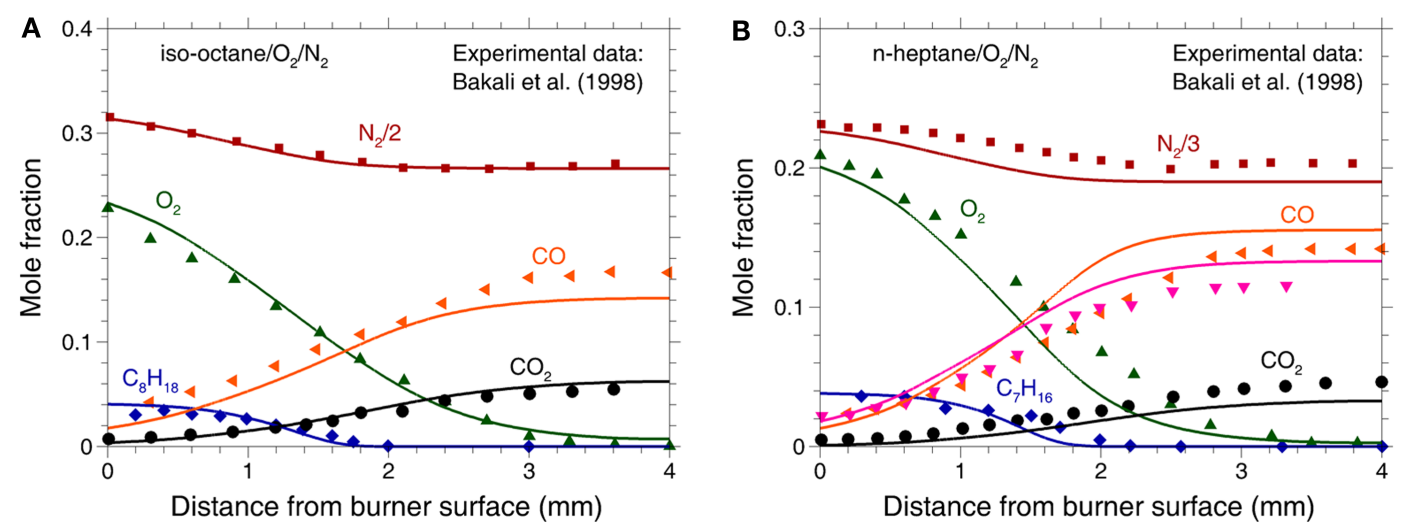

FIGURE 8 | Experimental (symbols) and predicted (lines) mole fractions of major species in a flat-flame burner at $\varphi=1.0$ and $p=0.1$ MPa for (A) iso-octane $/ \mathrm{O}_{2} / \mathrm{N}_{2}$ (Bakali et al., 1998) and (B) $n$-heptane $/ \mathrm{O}_{2} / \mathrm{N}_{2}$ (Bakali et al., 1998).
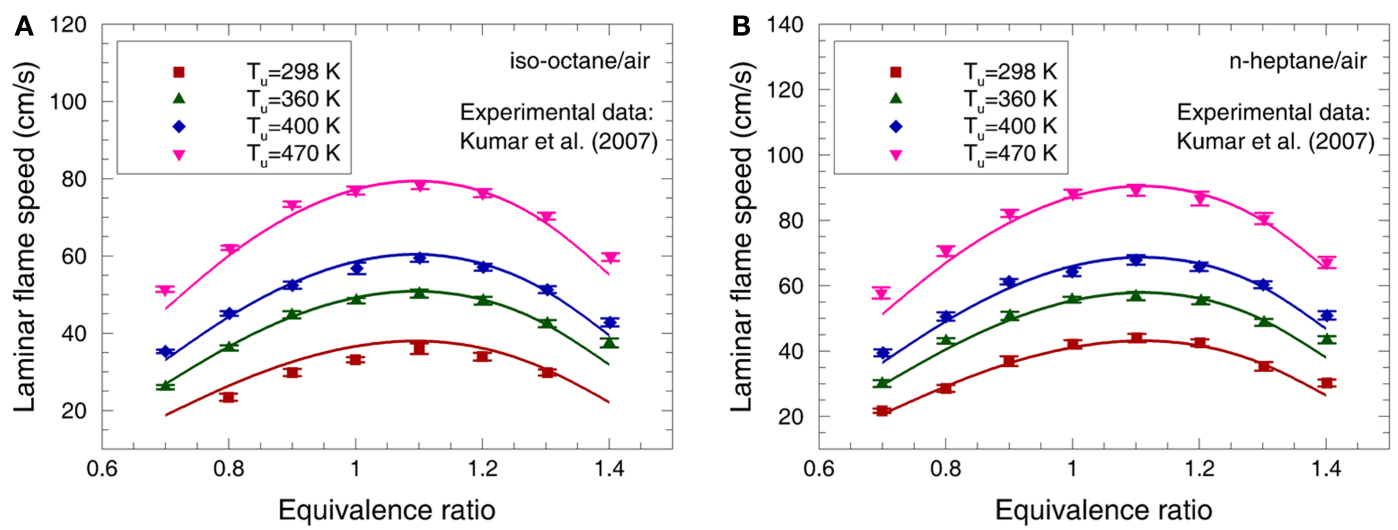

FIGURE 9 | Experimental (symbols) and predicted (lines) laminar flame speeds at $0.1 \mathrm{MPa}$ for (A) iso-octane/air mixture and (B) $n$-heptane/air mixture (Kumar et al., 2007). 

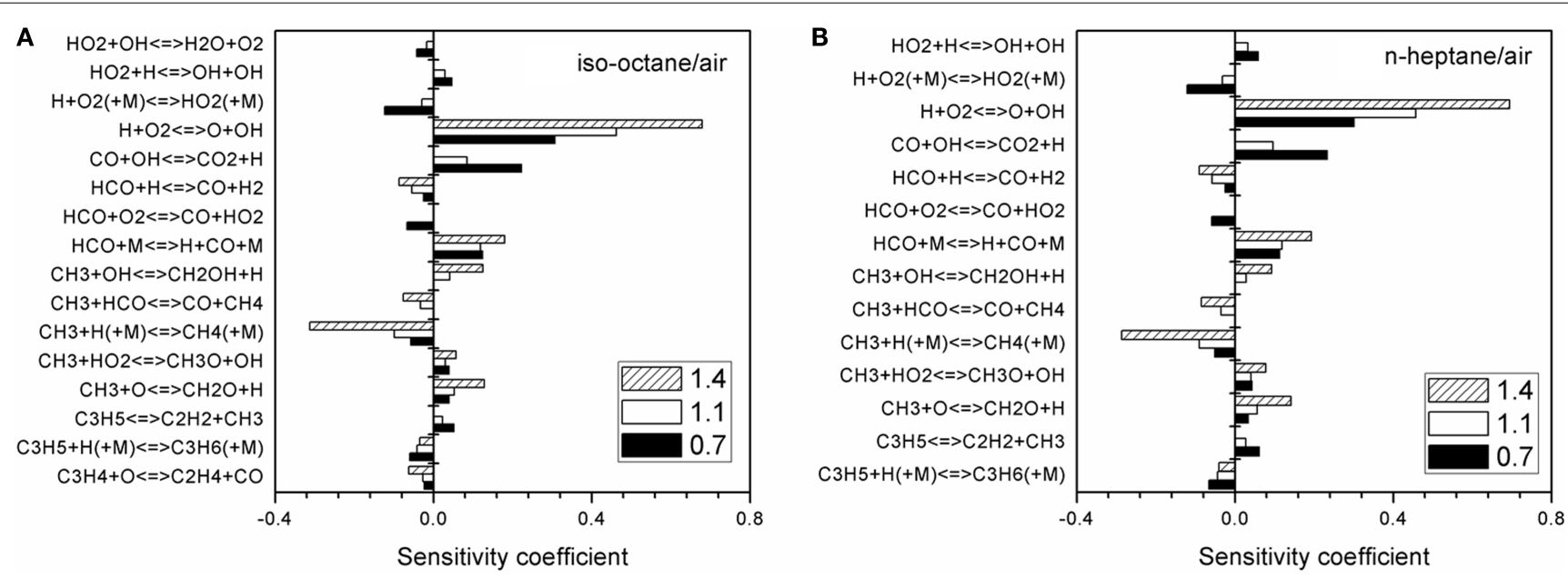

FIGURE 10 | Sensitivity analysis of laminar flame speed at $\varphi=0.7,1.1$, and 1.4 with $p=0.1 \mathrm{MPa}$ and $T_{\mathrm{u}}=360 \mathrm{~K}$ for $(\mathrm{A})$ iso-octane/air and (B) $n$-heptane/air.

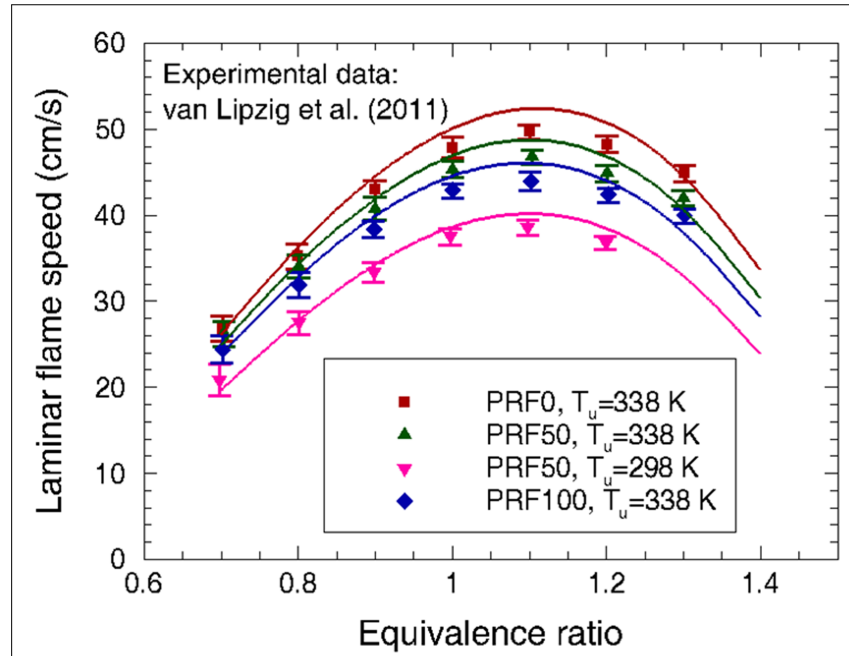

FIGURE 11 | Experimental (symbols) and predicted (lines) laminar flame speeds at 0.1 MPa for PRF fuels/air mixtures (Van Lipzig et al., 2011).

unburned temperature and equivalence ratio very well for both iso-octane/air and $n$-heptane/air flames.

A sensitivity analysis is carried out covering the equivalence ratios of $0.7,1.1$, and 1.4 at $T_{\mathrm{u}}=400 \mathrm{~K}$ and $p=0.1 \mathrm{MPa}$ in Figure 10. As can be seen, the reactions with high sensitivity coefficient are similar for both iso-octane/air and $n$-heptane/air flames, which are primarily the reactions in the $\mathrm{CH}_{3}, \mathrm{HCO}$, and $\mathrm{H}_{2}$ chemistry. Thus, accurate $\mathrm{CH}_{3}, \mathrm{HCO}$, and $\mathrm{H}_{2}$ sub-mechanism is crucial for the prediction of laminar flame speed.

Van Lipzig et al. (2011) determined the laminar flame speed of various PRFs at $p=0.1 \mathrm{MPa}$ and $T_{\mathrm{u}}=298$ and $338 \mathrm{~K}$ using a perforated plate burner. The predicted laminar flame speeds of PRF0, PRF50, and PRF100 are compared to the experimental data in Figure 11. As can be observed, the laminar flame speed increases with the decrease of $\mathrm{ON}$, which is satisfactorily reproduced by the present mechanism. Moreover, the increase

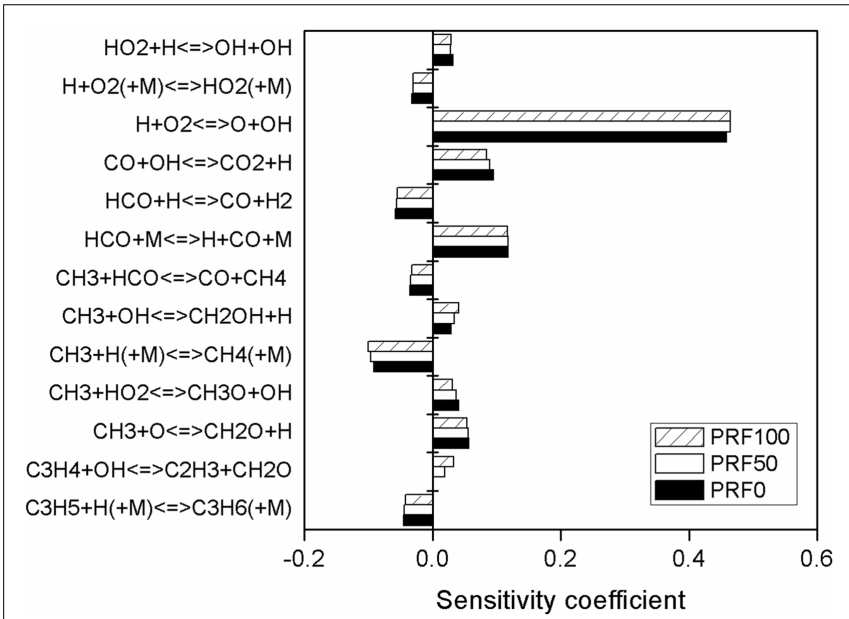

FIGURE 12 Sensitivity analysis of laminar flame speed at $\varphi=1.1$, $p=0.1 \mathrm{MPa}$, and $T_{\mathrm{u}}=338 \mathrm{~K}$ for PRF0, PRF50, and PRF100.

of unburned temperature leading to higher flame speed is also captured well. Overall, the agreement between the measurements and predictions is satisfactory with the maximum discrepancy of $2 \mathrm{~cm} / \mathrm{s}$, which is within the experimental uncertainty.

Figure 12 compares the sensitivity coefficients of PRF0, PRF50, and PRF100 at $T_{\mathrm{u}}=338 \mathrm{~K}$ and $\varphi=1.1$. Although the reactions with large sensitivity coefficients are same for the three PRFs, the magnitudes of sensitivity coefficients are different, which suggests that the difference in the small hydrocarbons concentration leads to the variation of laminar flame speed for the three PRFs. The analysis of the flame structures for the three PRF fuels are illustrated in Figure 13 by comparing the temperature, $\mathrm{H}$, and $\mathrm{CH}_{3}$ profiles at $T_{\mathrm{u}}=338 \mathrm{~K}$ and $\varphi=1.0$. As can be seen, the temperature profiles of the three fuels are similar, which indicates that the difference in laminar flame speed for the three PRFs is not caused by the flame temperature. For $\mathrm{CH}_{3}$ radical, its concentration increases with increased $\mathrm{ON}$. The higher concentration of $\mathrm{CH}_{3}$ leads to lower laminar flame speed due to 


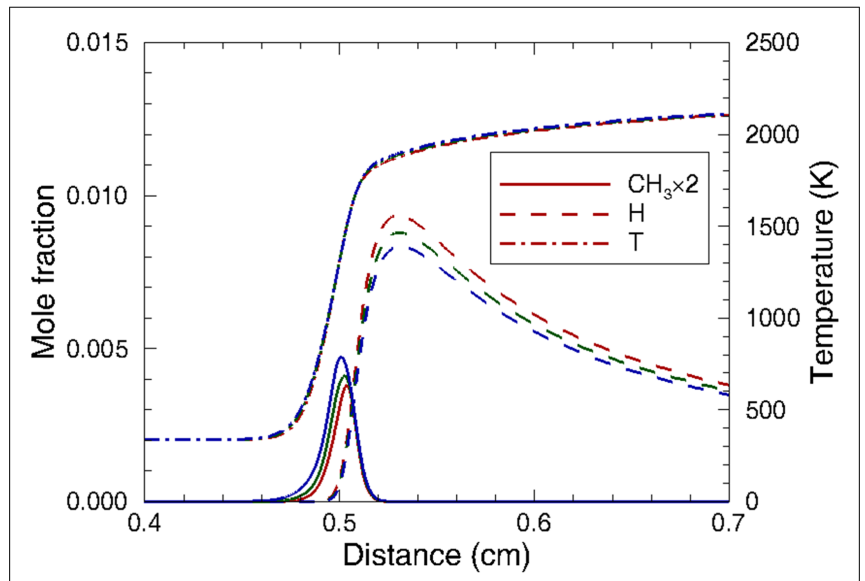

FIGURE 13 | Comparison of predicted temperature and the relevant radicals profiles for PRFO (red lines), PRF50 (green lines), and PRF100 (blue lines) at $T_{\mathrm{u}}=338 \mathrm{~K}, \varphi=1.0$, and $p=0.1 \mathrm{MPa}$.

its inhibition effect on flame propagation (Ji et al., 2012; Ranzi et al., 2012). A major pathway for the formation of $\mathrm{CH}_{3}$ radical is the decomposition of $i \mathrm{C}_{4} \mathrm{H}_{9}$ (R31) (Ji et al., 2012). Because of the branched structure of iso-octane (PRF100), more $i \mathrm{C}_{4} \mathrm{H}_{9}$ tends to be formed by the decomposition of $i \mathrm{C}_{8} \mathrm{H}_{17}$ (R18) and ${ }_{i} \mathrm{C}_{8} \mathrm{H}_{16}$ (R27) at high temperatures, resulting in higher $\mathrm{CH}_{3}$ concentration. Consequently, laminar flame speed decreases with the increase of ON, as shown in Figure 11. By contrast, the $\mathrm{H}$ radical exhibits the opposite trend with the variation of $\mathrm{ON}$. The $\mathrm{H}$ radical accelerates laminar flame speed due to the large positive sensitivity coefficient of the chain-branching reaction of $\mathrm{H}+\mathrm{O}_{2} \Leftrightarrow \mathrm{O}+\mathrm{OH}$ (R69) (see Figure 12) (Ranzi et al., 2012). Thus, due to the higher $\mathrm{H}$ concentration with smaller $\mathrm{ON}$, laminar flame speed increases simultaneously.

\section{HCCI Engine}

In this section, the PRF mechanism is coupled with multidimensional CFD model to simulate the combustion and emission characteristics of HCCI engines fueled with iso-octane and various PRFs. The simulation was performed by implementing the CHEMKIN-PRO Release 15101 (2010) into the KIVA-3V code (Amsden, 1997) to couple the chemistry and flow solutions. The KIVA code is updated by using the renormalization group (RNG) $k-\varepsilon$ turbulence model (Han and Reitz, 1995). Moreover, the heat transfer model developed by Han and Reitz (1997) was employed, in which the variation of gas density in the boundary layer is taken into account. The turbulence-chemistry interaction is neglected in this study, and the perfectly stirred reactor (PSR) model is introduced owing to the spontaneous combustion of the premixed charge in HCCI engines. More details about the computational models can be found in Jia and Xie (2007).

It must be noted that the computational results of HCCI engines are sensitive to the initial temperature at intake valve closing (IVC) and the cylinder wall temperature. In this study, the temperatures of cylinder wall, piston face, and cylinder head used in the CFD simulations are mainly determined according to experimental
TABLE 1 | Engine specifications and operating conditions

\begin{tabular}{lcc}
\hline & Dec and Sjöberg (2003) & Dempsey et al. (2013) \\
\hline Displacement $(\mathrm{L})$ & 0.981 & 0.477 \\
Bore $(\mathrm{mm}) \times$ Stork $(\mathrm{mm})$ & $102 \times 192$ & $82 \times 90.4$ \\
Compression ratio & $18: 1$ & $17.4: 1$ \\
IVC $^{\mathrm{a}}$ & $-155^{\circ} \mathrm{ATDC}^{\mathrm{C}}$ & $-132^{\circ} \mathrm{ATDC}^{\mathrm{C}}$ \\
$\mathrm{EVO}^{\mathrm{b}}$ & $120^{\circ} \mathrm{ATDC}^{\mathrm{C}}$ & $112^{\circ} \mathrm{ATDC}^{\mathrm{C}}$ \\
Engine speed $(\mathrm{rev} / \mathrm{min})$ & 1200 & 1500 \\
Intake temperature $\left({ }^{\circ} \mathrm{C}\right)$ & 140 & 90 \\
Intake pressure $(\mathrm{kPa})$ & 120 & 110 \\
Equivalence ratio & $0.06-0.26$ & 0.26 \\
Fuel & iso-Octane & PRFs
\end{tabular}

a IVC, intake valve closing.

${ }^{b} E V O$, exhaust valve opening.

${ }^{c}$ ATDC, after top dead center.

measurements. However, due to the influence of heat transfer in the port, heating the charge by flow turbulence, charge cooling due to fuel vaporization, and mixing with residuals (Sjöberg and Dec, 2004), the initial temperature at IVC is difficult to be determined experimentally (Kong and Reitz, 2003; Kong et al., 2003). Thus, the initial temperature is found to be the most uncertain factor in the simulation. In this study, the initial temperature at IVC was adjusted in such a way that the computed pressure trace could match the experiment in the whole combustion process. It is found that the initial temperature for the model is always higher than the measured intake air temperature for the test cases.

Dec and Sjöberg (2003) performed a set of experiments to investigate the sources of $\mathrm{CO}$ and $\mathrm{HC}$ emissions in a HCCI engine fueled with iso-octane. The detailed engine specifications are listed in Table 1. An axisymmetric grid shown in Figure 14A is employed for the simulation in the present study. Comparisons between the measured and calculated in-cylinder pressures and $\mathrm{HC}, \mathrm{CO}$, and carbon dioxide $\left(\mathrm{CO}_{2}\right)$ emissions at the equivalence ratios of 0.06-0.26 are shown in Figure 15A. It can be seen that the predictions agree very well with the experimental data at various equivalence ratios. In the previous mechanism (Liu et al., 2013), the in-cylinder pressure is overpredicted before the hot ignition due to the overestimation of the first-stage heat release rate. In the present mechanism, the introduction of $i \mathrm{C}_{4} \mathrm{H}_{8}$ as a major intermediate and the improved $\mathrm{C}_{2}$ sub-mechanism can considerably improve the predictions on the first- and second-stage heat release processes. The high stability of $i \mathrm{C}_{4} \mathrm{H}_{8}$ leads to low reactivity of the fuel/air mixture, which retards the rise of the in-cylinder pressure before hot ignition. Therefore, the in-cylinder pressure during the whole working processes is reproduced reasonably well using the present mechanism, as shown in Figure 15A. Moreover, since a detailed $\mathrm{H}_{2} / \mathrm{CO} / \mathrm{C}_{1}$ mechanism is employed, the emissions of $\mathrm{HC}$, $\mathrm{CO}$, and $\mathrm{CO}_{2}$ can also be satisfactorily reproduced by the present mechanism.

Dempsey et al. (2013) conducted a series of experiments in a HCCI engine fueled with various PRFs. The experimental data at the intake temperature of $90^{\circ} \mathrm{C}$ and equivalence ratio of 0.26 are used to validate the present mechanism. In the simulation, a $51.43^{\circ}(1 / 7$ th cylinder $)$ mesh is employed, as shown in Figure 14B. Figure 15B depicts comparisons of the measured and predicted 

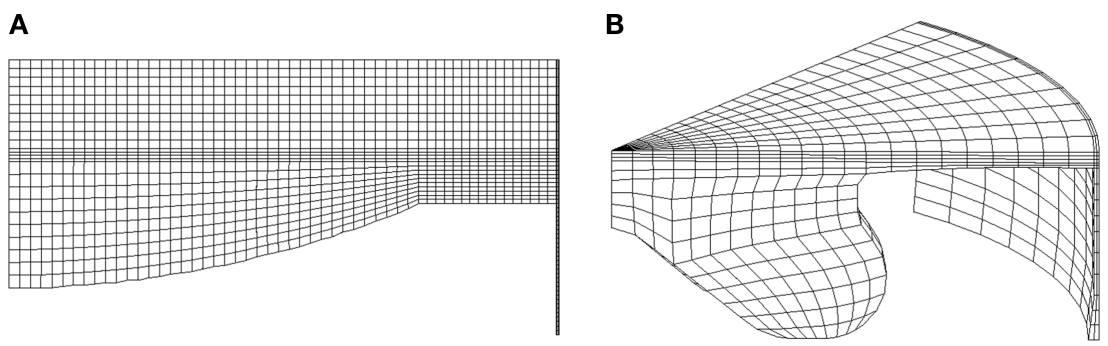

FIGURE 14 | Computational grids at top dead center for engine simulations for (A) Dec and Sjöberg (2003) and (B) Dempsey et al. (2013).
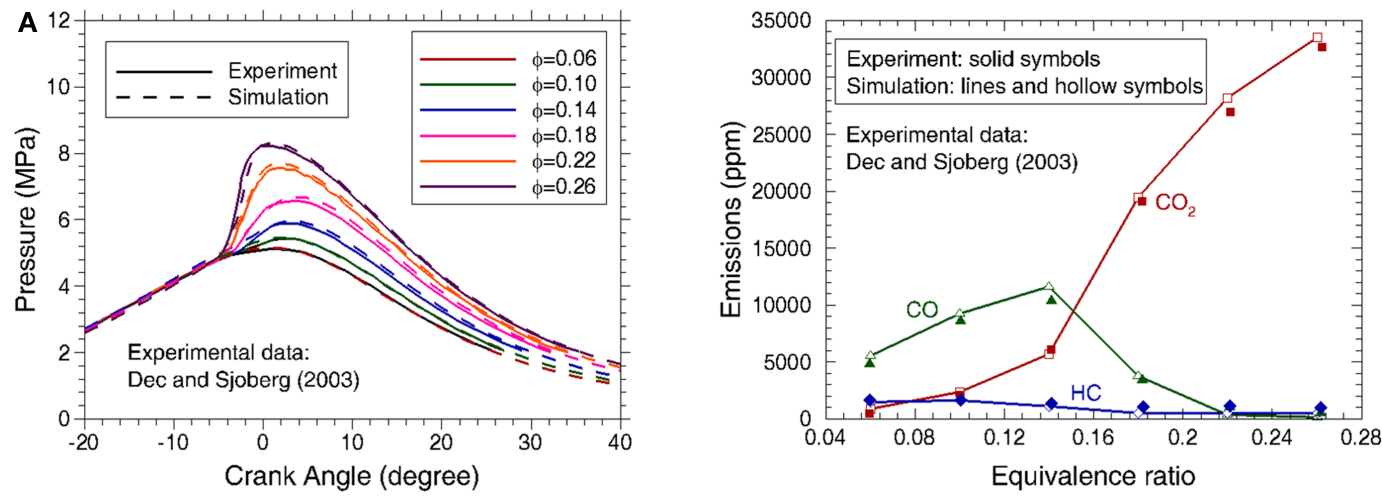

HCCI engine fueled with iso-octane
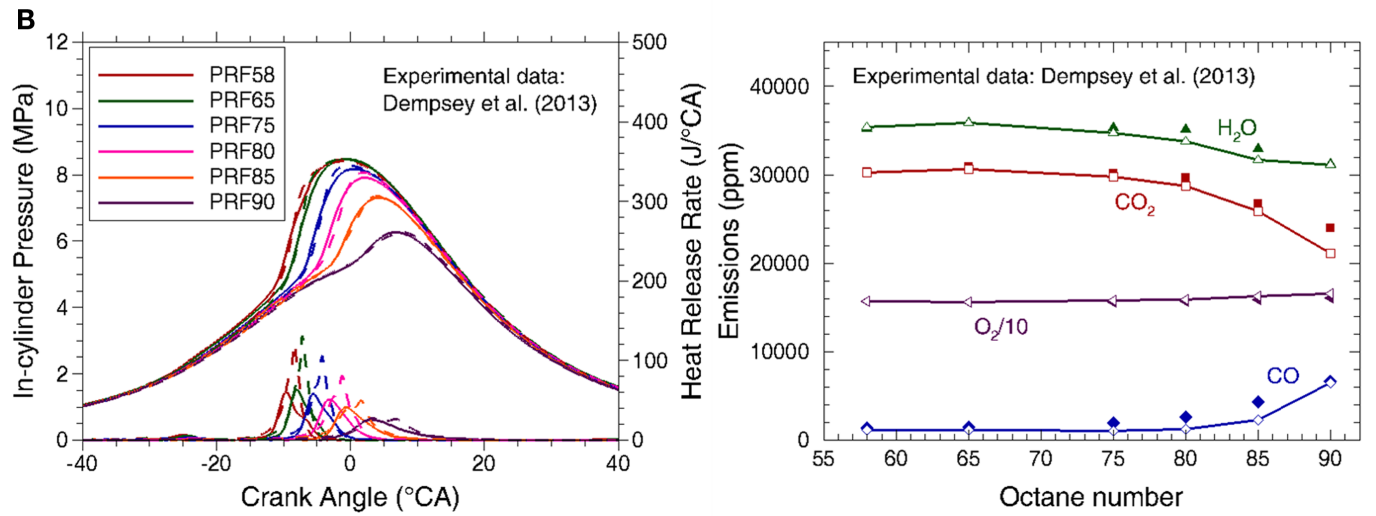

HCCI engine fueled with PRFs

FIGURE 15 | Experimental (symbols) and predicted (lines) in-cylinder pressures, heat release rate files, exhaust $\mathrm{CO}_{2}, \mathrm{CO} \mathrm{HC}, \mathrm{O}_{2}$, and $\mathrm{H}_{2} \mathrm{O}$ emissions in a $\mathrm{HCCl}$ engine fueled with (A) iso-octane (Dec and Sjöberg, 2003) and (B) various PRFs (Dempsey et al.., 2013).

in-cylinder pressure and heat release rate, as well as $\mathrm{CO}, \mathrm{O}_{2}$, $\mathrm{CO}_{2}$, and $\mathrm{H}_{2} \mathrm{O}$ emissions for various PRFs. It can be seen that the present mechanism reproduces the experimental data very well, especially for the in-cylinder pressures and emissions. Furthermore, the increase of $\mathrm{ON}$ resulting in reduced peak pressure and heat release rate, as well as retarded ignition timing and higher $\mathrm{CO}$ emissions is also accurately captured, although the peak heat release rate is overpredicted and becomes unsmooth for PRF90. Several factors could contribute to these discrepancies, including the uncertainties in the initial conditions, the chemistry mechanism, and the computational model, as well as the different methods used to determine the heat release rate in the simulation and experiment. In the experiment of Dempsey et al. $(2013,2014)$, the heat release rate is derived from the measured average in-cylinder pressure, while the predicted heat release rate is directly obtained by calculating the heat that chemical reaction released heat minuses the in-cylinder wall transfer heat. The pressure used in the experiment is averaged with assumption of the uniform in-cylinder pressure and temperature, thus the heat release rate derived from experiment is less than that from the 
simulation due to the local high-temperature combustion being neglected.

\section{Conclusion}

Based on recent theoretical and experimental developments, several improvements are introduced into the decoupling methodology for the construction of the mechanisms of large-molecule fuels, which can be summarized as follows. First, the $\mathrm{H}_{2} / \mathrm{O}_{2}$ chemistry is replaced with the newest work of Burke et al. (2012). Second, the rate constants of the reactions involving $\mathrm{HCO} / \mathrm{CH}_{3} / \mathrm{CH}_{2} \mathrm{O}$ are updated according to the Metcalfe et al. (2013) mechanism. Third, a new $C_{2}$ sub-mechanism is obtained by sensitivity analysis and pathway analysis on the detailed mechanisms of Ji et al. (2012); Ranzi et al. (2012), and Metcalfe et al. (2013). Finally, the fuel-specific sub-mechanism is improved by removing the arbitrarily specified reverse reaction rates.

Using the improved decoupling methodology, a new PRF skeletal mechanism is developed. The final PRF mechanism contains 49 species and 163 reactions. By comparing with the experimental data in fundamental reactors, it is found that the present mechanism is capable of accurately predicting the ignition delay times in shock tubes, major species concentrations in JSRs and premixed laminar flames, and laminar flame speed for various PRFs over a wide range of operating conditions. Moreover, by coupling the PRF mechanism with a CFD code, the in-cylinder pressure and heat release rate, $\mathrm{CO}, \mathrm{HC}$, and $\mathrm{CO}_{2}$ emissions in HCCI engines fueled with iso-octane and PRFs can also satisfactorily reproduced. Compared to the latest reduced PRF mechanisms, the present mechanism can accurately predict the ignition delay time in shock tubes, major species concentration in JSRs, and laminar flame speed for various PRFs over low-to-high temperature and a wide pressure range. Moreover, the size of the present mechanism is relatively small with only 49 species and 163 reactions, which reduces the computational time, especially for 3D CFD simulations.

\section{References}

Amsden, A. A. (1997). KIVA-3V: A Block-Structured KIVA Program for Engines with Vertical or Canted Values. Technical Report, LA-13313-MS. Los Alamos: Los Alamos National Laboratory.

Andrae, J., Johansson, D., Bjornbom, P., Risberg, P., and Kalghatgi, G. (2005). Cooxidation in the auto-ignition of primary reference fuels and n-heptane/toluene blends. Combust. Flame 140, 267-286. doi:10.1016/j.combustflame.2004.11.009

Babushok, V. I., and Tsang, W. (2004). Kinetic modeling of heptane combustion and pah formation. J. Propul. Power 20, 403-414. doi:10.2514/1.2323

Bakali, A. E., Delfau, J. L., and Vovelle, C. (1998). Experimental study of 1 atmosphere, rich, premixed n-heptane and iso-octane flames. Combust. Sci. Technol. 140, 69-91. doi:10.1080/00102209808915768

Bikas, G., and Peters, N. (2001). Kinetic modelling of n-decane combustion and autoignition. Combust. Flame 126, 1456-1475. doi:10.1016/s0010-2180(01) 00254- 1

Burke, M. P., Chaos, M., Ju, Y., Dryer, F. L., and Klippenstein, S. J. (2012). Comprehensive h2/o2 kinetic model for high-pressure combustion. Int. J. Chem. Kinet. 44, 444-474. doi:10.1002/kin.20603

Campbell, M. F., Wang, S., Goldenstein, C. S., Spearrin, R. M., Tulgestke, A. M., Zaczek, L. T., et al. (2015). Constrained reaction volume shock tube study of $\mathrm{n}$-heptane oxidation: ignition delay times and time-histories of multiple
According to the sensitivity analysis on ignition delay time and laminar flame speed, it is found that the $\mathrm{CH}_{3}, \mathrm{HCO}$, and $\mathrm{H}_{2} / \mathrm{O}_{2}$ chemistry plays important roles in auto-ignition and flame propagation characteristics for PRF/air mixture. Thus, a refinement on the related reactions notably improves the predictions on ignition delay time and laminar flame speed. Although the predicted ignition delay time and laminar flame speed are insensitive to the reactions involving $\mathrm{C}_{2}$ species, as the transition between fuel molecule and small species, the reaction paths of $\mathrm{C}_{2}$ species affect the formation of small species. Therefore, a reliable $C_{2}$ submechanism is still very crucial for the development of the PRF mechanism. Overall, with the enhancement of the $\mathrm{H}_{2} / \mathrm{CO} / \mathrm{C}_{1}-\mathrm{C}_{2}$ chemistry and the improved large-molecule reaction rates in the decoupling methodology, the present PRF mechanism shows satisfactorily performance in both fundamental reactors and practical engines under a wide range of operating conditions, which proves the potential of the application of the decoupling methodology for the development of skeletal mechanisms for long-chain hydrocarbons.

\section{Acknowledgments}

The financial support from the National Natural Science Foundation of China (Grant No. 51476020) and National Basic Research Project of China (Grant No. 2013CB228400) are greatly appreciated. The authors are also thankful to Prof. Rolf D. Reitz for providing the HCCI experimental data.

\section{Supplementary Material}

The mechanism in CHEMKIN format and comparison of the predictions from the latest skeletal/reduced PRF mechanisms with the present mechanism are provided as supplementary material which can be found online at http://journal.frontiersin.org/ article/10.3389/fmech.2015.00011

species and temperature. Proc. Combust. Inst. 35, 231-239. doi:10.1016/j.proci. 2014.05.001

Chang, Y., Jia, M., Liu, Y., Li, Y., and Xie, M. (2013a). Development of a new skeletal mechanism for $\mathrm{n}$-decane oxidation under engine-relevant conditions based on a decoupling methodology. Combust. Flame 160, 1315-1332. doi:10. 1016/j.combustflame.2013.02.017

Chang, Y., Jia, M., Liu, Y., Li, Y., Xie, M., and Yin, H. (2013b). Application of a decoupling methodology for development of skeletal oxidation mechanisms for heavy n-alkanes from n-octane to n-hexadecane. Energy Fuels 27, 3467-3479. doi:10.1021/ef400460d

Chaos, M., Kazakov, A., Zhao, Z., and Dryer, F. L. (2007). A high-temperature chemical kinetic model for primary reference fuels. Int. J. Chem. Kinet. 39, 399-414. doi:10.1002/kin.20253

CHEMKIN-PRO Release 15101. (2010). A Chemical Kinetics Package for the Analysis of Gas-Phase Chemical Kinetics. San Diego, CA: Reaction Design, Inc.

Ciezki, H. K., and Adomeit, G. (1993). Shock-tube investigation of self-ignition of n-heptane-air mixtures under engine relevant conditions. Combust. Flame 93, 421-433. doi:10.1016/0010-2180(93)90142-P

Contino, F., Jeanmart, H., Lucchini, T., and D'errico, G. (2011). Coupling of in situ adaptive tabulation and dynamic adaptive chemistry: an effective method for solving combustion in engine simulations. Proc. Combust. Inst. 33, 3057-3064. doi:10.1016/j.proci.2010.08.002 
Dagaut, P., Reuillon, M., and Cathonnet, M. (1993). High pressure oxidation of liquid fuels from low to high temperature. 1. N-heptane and iso-octane. Combust. Sci. Technol. 95, 233-260. doi:10.1080/00102209408935336

Dagaut, P., Reuillon, M., and Cathonnet, M. (1994). High pressure oxidation of liquid fuels from low to high temperature. 2. Mixtures of n-heptane and isooctane. Combust. Sci. Technol. 103, 315-336. doi:10.1080/00102209408907701

Dec, J. E., and Sjöberg, M. (2003). A parametric study of HCCI combustion - the sources of emissions at low loads and the effects of GDI fuel injection. SAE Paper 2003-01-0752. Detroit, MI.

Dempsey, A. B., Walker, N. R., Gingrich, E., and Reitz, R. D. (2014). Comparison of low temperature combustion strategies for advanced compression ignition engines with a focus on controllability. Combust. Sci. Technol. 186, 210-241. doi:10.1080/00102202.2013.858137

Dempsey, A. B., Walker, N. R., and Reitz, R. (2013). Effect of cetane improvers on gasoline, ethanol, and methanol reactivity and the implications for RCCI combustion. SAE Int. J. Fuels Lubr. 6, 170-187. doi:10.4271/2013-011678

Farrell, J. T., Cernansky, N. P., Dryer, F. L., Law, C. K., Friend, D. G., Hergart, C. A., et al. (2007). Development of an experimental database and kinetic models for surrogate diesel fuels. SAE Paper 2007-01-0201. Detroit, MI.

Fieweger, K., Blumenthal, R., and Adomeit, G. (1997). Self-ignition of S.I. Engine model fuels: a shock tube investigation at high pressure. Combust. Flame 109, 599-619. doi:10.1016/S0010-2180(97)00049-7

Gauthier, B. M., Davidson, D. F., and Hanson, R. K. (2004). Shock tube determination of ignition delay times in full-blend and surrogate fuel mixtures. Combust. Flame 139, 300-311. doi:10.1016/j.combustflame.2004.08.015

Han, Z. W., and Reitz, R. D. (1995). Turbulence modeling of internal combustion engnies using rng $k$ - $\varepsilon$ models. Combust. Sci. Technol. 106, 267-295. doi:10.1080/ 00102209508907782

Han, Z. W., and Reitz, R. D. (1997). A temperature wall function formulation for variable-density turbulence flows with application to engines convective heat transfer modeling. Int. J. Heat Mass Transfer 40, 613-625. doi:10.1016/00179310(96)00117-2

Hansen, N., Cool, T. A., Westmoreland, P. R., and Kohse-Höinghaus, K. (2009). Recent contributions of flame-sampling molecular-beam mass spectrometry to a fundamental understanding of combustion chemistry. Prog. Energy Combust. Sci. 35, 168-191. doi:10.1016/j.pecs.2008.10.001

Herbinet, O., Husson, B., Serinyel, Z., Cord, M., Warth, V., Fournet, R., et al. (2012). Experimental and modeling investigation of the low-temperature oxidation of n-heptane. Combust. Flame 159, 3455-3471. doi:10.1016/j.combustflame.2012. 07.008

Heufer, K. A., and Olivier, H. (2010). Determination of ignition delay times of different hydrocarbons in a new high pressure shock tube. Shock Waves 20, 307-316. doi:10.1007/s00193-010-0262-2

Ji, C., Dames, E., Wang, Y. L., Wang, H., and Egolfopoulos, F. N. (2010). Propagation and extinction of premixed c5-c12 n-alkane flames. Combust. Flame 157, 277-287. doi:10.1016/j.combustflame.2009.06.011

Ji, C., Sarathy, S. M., Veloo, P. S., Westbrook, C. K., and Egolfopoulos, F. N. (2012). Effects of fuel branching on the propagation of octane isomers flames. Combust. Flame 159, 1426-1436. doi:10.1016/j.combustflame.2011.12.004

Jia, M., and Xie, M. (2007). Numerical simulation of homogeneous charge ignition combustion using a multi-dimensional model. Proc. Inst. Mech. Eng. Part D: J. Automobile Eng. 221, 465-480. doi:10.1243/09544070jauto263

Kong, S. C., and Reitz, R. D. (2003). Numerical study of premixed HCCI engine combustion and its sensitivity to computational mesh and model uncertainties. Combust. Theory Model. 7, 417-433. doi:10.1088/1364-7830/7/2/ 312

Kong, S. C., Reitz, R. D., Christensen, M., and Johansson, B. (2003). Modeling the effects of geometry generated turbulence on HCCI engine combustion. SAE Paper 2003-01-1008. Detroit, MI.

Kumar, K., Freeh, J. E., Sung, C. J., and Huang, Y. (2007). Laminar flame speeds of preheated iso-octane/o2/n2 and n-heptane/o2/n2 mixtures. J. Propul. Power 23, 428-436. doi:10.2514/1.24391

Lam, S. H., and Goussis, D. A. (1994). The csp method for simplifying kinetics. Int. J. Chem. Kinet. 26, 461-486. doi:10.1002/kin.550260408

Li, J., Zhao, Z., Kazakov, A., Chaos, M., Dryer, F. L., and Scire, J. J. (2007). A comprehensive kinetic mechanism for co, ch2o, and ch3oh combustion. Int. J. Chem. Kinet. 39, 109-136. doi:10.1002/kin.20218
Li, J., Zhao, Z., Kazakov, A., and Dryer, F. L. (2004). An updated comprehensive kinetic model of hydrogen combustion. Int. J. Chem. Kinet. 36, 566-575. doi:10. 1002/kin.20026

Li, X., You, X., Wu, F., and Law, C. K. (2015). Uncertainty analysis of the kinetic model prediction for high-pressure h2/co combustion. Proc. Combust. Inst. 35, 617-624. doi:10.1016/j.proci.2014.07.047

Liang, L., Stevens, J. G., and Farrell, J. T. (2009). A dynamic adaptive chemistry scheme for reactive flow computations. Proc. Combust. Inst. 32 I, 527-534. doi:10.1016/j.proci.2008.05.073

Liu, Y., Jia, M., Xie, M., and Pang, B. (2013). Improvement on a skeletal chemical kinetic model of iso-octane for internal combustion engine by using a practical methodology. Fuel 103, 884-891. doi:10.1016/j.fuel.2012.07.046

Liu, Y. D., Jia, M., Xie, M. Z., and Pang, B. (2012). Enhancement on a skeletal kinetic model for primary reference fuel oxidation by using a semidecoupling methodology. Energy Fuels 26, 7069-7083. doi:10.1021/ef301242b

Lu, T., and Law, C. K. (2005). A directed relation graph method for mechanism reduction. Proc. Combust. Inst. 30, 1333-1341. doi:10.1016/j.proci.2004.08.145

Lu, T., and Law, C. K. (2006). On the applicability of directed relation graphs to the reduction of reaction mechanisms. Combust. Flame 146, 472-483. doi:10.1016/ j.combustflame.2006.04.017

Luong, M. B., Luo, Z., Lu, T., Chung, S. H., and Yoo, C. S. (2013). Direct numerical simulations of the ignition of lean primary reference fuel/air mixtures with temperature inhomogeneities. Combust. Flame 160, 2038-2047. doi:10.1016/j. combustflame.2013.04.012

Mehl, M., Pitz, W. J., Westbrook, C. K., and Curran, H. J. (2011). Kinetic modeling of gasoline surrogate components and mixtures under engine conditions. Proc. Combust. Inst. 33, 193-200. doi:10.1016/j.proci.2010.05.027

Metcalfe, W. K., Burke, S. M., Ahmed, S. S., and Curran, H. J. (2013). A hierarchical and comparative kinetic modeling study of c1-c2hydrocarbon and oxygenated fuels. Int. J. Chem. Kinet. 45, 638-675. doi:10.1002/kin.20802

Narayanaswamy, K., Pepiot, P., and Pitsch, H. (2014). A chemical mechanism for low to high temperature oxidation of n-dodecane as a component of transportation fuel surrogates. Combust. Flame 161, 866-884. doi:10.1016/j.combustflame. 2013.10.012

Patel, A., Kong, S., and Reitz, R. (2004). Development and validation of a reduced reaction mechanism for HCCI engine simulations. SAE Paper 2004-01-0558, Detroit, MI.

Pope, S. B. (1997). Computationally efficient implementation of combustion chemistry using in situ adaptive tabulation. Combust. Theory Model. 1, 41-63. doi:10. 1088/1364-7830/1/1/006

Ra, Y., and Reitz, R. D. (2008). A reduced chemical kinetic model for IC engine combustion simulations with primary reference fuels. Combust. Flame 155, 713-738. doi:10.1016/j.combustflame.2008.05.002

Ra, Y., and Reitz, R. D. (2011). A combustion model for IC engine combustion simulations with multi-component fuels. Combust. Flame 158, 69-90. doi:10. 1016/j.combustflame.2010.07.019

Ranzi, E. (2006). A wide-range kinetic modeling study of oxidation and combustion of transportation fuels and surrogate mixtures. Energy Fuels 20, 1024-1032. doi:10.1021/ef060028h

Ranzi, E., Frassoldati, A., Grana, R., Cuoci, A., Faravelli, T., Kelley, A. P., et al. (2012). Hierarchical and comparative kinetic modeling of laminar flame speeds of hydrocarbon and oxygenated fuels. Prog. Energy Combust. Sci. 38, 468-501. doi:10.1016/j.pecs.2012.03.004

Reitz, R. D., and Duraisamy, G. (2015). Review of high efficiency and clean reactivity controlled compression ignition (RCCI) combustion in internal combustion engines. Prog. Energy Combust. Sci. 46, 12-71. doi:10.1016/j.pecs.2014.05.003

Shen, H.-P. S., Steinberg, J., Vanderover, J., and Oehlschlaeger, M. A. (2009). A shock tube study of the ignition of n-heptane, n-decane, n-dodecane, and ntetradecane at elevated pressures. Energy Fuels 23, 2482-2489. doi:10.1021/ ef8011036

Shen, H.-P. S., Vanderover, J., and Oehlschlaeger, M. A. (2008). A shock tube study of iso-octane ignition at elevated pressures: the influence of diluent gases. Combust. Flame 155, 739-755. doi:10.1016/j.combustflame.2008.06.001

Sjöberg, M., and Dec, J. E. (2004). An investigation of the relationship between measured intake temperature, BDC temperature, and combustion phasing for premixed and DI HCCI engines. SAE Paper 2004-01-1900, Toulouse.

Skeen, S. A., Yang, B., Jasper, A. W., Pitz, W. J., and Hansen, N. (2011). Chemical structures of low-pressure premixed methylcyclohexane flames as benchmarks 
for the development of a predictive combustion chemistry model. Energy Fuels 25, 5611-5625. doi:10.1021/ef201507x

Tanaka, S., Ayala, F., and Keck, J. C. (2003). A reduced chemical kinetic model for HCCI combustion of primary reference fuels in a rapid compression machine. Combust. Flame 133, 467-481. doi:10.1016/s0010-2180(03)00057-9

Tomlin, A. S., Pilling, M. J., Turányi, T., Merkin, J. H., and Brindley, J. (1992). Mechanism reduction for the oscillatory oxidation of hydrogen: sensitivity and quasi-steady-state analyses. Combust. Flame 91, 107-130. doi:10.1016/00102180(92)90094-6

Van Lipzig, J. P. J., Nilsson, E. J. K., De Goey, L. P. H., and Konnov, A. A. (2011). Laminar burning velocities of $n$-heptane, iso-octane, ethanol and their binary and tertiary mixtures. Fuel 90, 2773-2781. doi:10.1016/j.fuel.2011.04.029

Vandersickel, A., Hartmann, M., Vogel, K., Wright, Y. M., Fikri, M., Starke, R., et al. (2012). The autoignition of practical fuels at HCCI conditions: high-pressure shock tube experiments and phenomenological modeling. Fuel 93, 492-501. doi:10.1016/j.fuel.2011.10.062

Vasu, S. S., Davidson, D. F., and Hanson, R. K. (2005). "Shock tube measurements and modeling of ignition delay times in lean iso-Octane/air," in 25th Int. Symp. on Shock Waves (Bangalore).

Wang, H., Yao, M., and Reitz, R. D. (2013). Development of a reduced primary reference fuel mechanism for internal combustion engine combustion simulations. Energy Fuels 27, 7843-7853. doi:10.1021/ef401992e
Warnatz, J. (1981). Structure of laminar alkane-, alkene-, and acetylene flames. Symp. Int. Combust. 18, 369-384. doi:10.1016/S0082-0784(81)80042-2

Westbrook, C. K., and Dryer, F. L. (1984). Chemical kinetic modeling of hydrocarbon combustion. Prog. Energy Combust. Sci. 10, 1-57. doi:10.1016/03601285(84)90118-7

Whitehouse, L. E., Tomlin, A. S., and Pilling, M. J. (2004). Systematic reduction of complex tropospheric chemical mechanisms, part i: sensitivity and time-scale analyses. Atmos. Chem. Phys. 4, 2025-2056. doi:10.5194/acp-4-2025-2004

Yao, M., Zheng, Z., and Liu, H. (2009). Progress and recent trends in homogeneous charge compression ignition (HCCI) engines. Prog. Energy Combust. Sci. 35, 398-437. doi:10.1016/j.pecs.2009.05.001

Conflict of Interest Statement: The authors declare that the research was conducted in the absence of any commercial or financial relationships that could be construed as a potential conflict of interest.

Copyright (C) 2015 Chang, Jia, Li and Xie. This is an open-access article distributed under the terms of the Creative Commons Attribution License (CC BY). The use, distribution or reproduction in other forums is permitted, provided the original author(s) or licensor are credited and that the original publication in this journal is cited, in accordance with accepted academic practice. No use, distribution or reproduction is permitted which does not comply with these terms. 